\title{
Rethinking interest rate volatility as a macroprudential policy tool
}

\section{Burak Dogan, Afsin Sahin \& M. Hakan Berument}

To cite this article: Burak Dogan, Afsin Sahin \& M. Hakan Berument (2016) Rethinking interest rate volatility as a macroprudential policy tool, Middle East Development Journal, 8:1, 109-126, DOI: $10.1080 / 17938120.2016 .1150009$

To link to this article: https://doi.org/10.1080/17938120.2016.1150009

册Published online: 18 Apr 2016.

Submit your article to this journal $\pi$

Џll Article views: 247

View Crossmark data \lceil

Citing articles: 1 View citing articles 


\title{
Rethinking interest rate volatility as a macroprudential policy tool
}

\author{
Burak Dogan $^{\mathrm{a} \dagger}$, Afsin Sahin ${ }^{\mathrm{b}}$ and M. Hakan Berument ${ }^{\mathrm{c} *}$ \\ ${ }^{a}$ Banking Regulation and Supervision Directorate, The Central Bank of the TRNC, Lefkosa, \\ Cyprus; ${ }^{b}$ Department of Banking, Gazi University, Ankara 06500, Turkey; ${ }^{c}$ Department of \\ Economics, Bilkent University, Ankara 06800, Turkey
}

(Received 19 August 2014; accepted 1 March 2015)

\begin{abstract}
Along with most other central banks, Turkey's central bank has implemented unconventional policies since the 2007/2008 financial crisis. Financial stability has been one of the targets of these macroprudential policies. However, since Turkey is working toward this goal without increasing its inflation rate, tracking only short-term interest rates to measure this policy's effectiveness would be inefficient. In this paper, we provide empirical evidence from Turkey that interbank interest rate volatility can be an additional tool for monetary policy makers to help achieve the goal of financial stability. Impulse responses generated from the Vector Autoregressive models indicate that interest rate volatility increases interest rates, depreciates domestic currency and decreases credit growth and output. Its statistically insignificant effect on prices is open to interpretation.
\end{abstract}

Keywords: economics; monetary policy; interest rate volatility; macroprudential policies

JEL Codes: E58; E52; E37

\section{Introduction}

After the 2007/2008 financial crisis, central banks started to experiment with new policy tools to conduct their monetary policies. Until the crisis, the direction of transition was away from directly controlling monetary aggregates to utilizing short-term interest rates to manage the financial markets. When the financial crisis revealed the weaknesses of such policies, monetary authorities were obliged to modify their tools, targets and means of transmission once more. In this context, our observation of the Central Bank of the Republic of Turkey's (CBRT) recent policy scheme, which could be described as a combination of credit, interest rate and liquidity policies to generate short-term interest rate volatility, is the main inspiration for this study. Thus, the purpose of this paper is to assess the effectiveness of this new tool on Turkey's macroeconomic performance. Our empirical evidence reported here suggests that interest rate volatility increases interest rates, depreciates the domestic currency and decreases credit growth and output.

\footnotetext{
*Corresponding author. Email: berument@bilkent.edu.tr

${ }^{\dagger}$ The views expressed here do not necessarily represent the official position of the Central Bank of the Turkish Republic of Northern Cyprus. 
As a global policy practice, financial stability now appears to be inserted into monetary models by capturing (or by being supported by) discretionary measures. ${ }^{1}$ Socalled unconventional policies have been mostly characterized by central banks expanding and compositionally changing their balance sheets as a result of their liquidity adjustments in financial markets (Carvalho, Eusepi, \& Grisse, 2012). The literature has already accumulated a significant number of studies on achieving effective monetary policy through unconventional means. For instance, noting the increased volatility of interest rate spreads during the 2007/2008 crisis, Gerlach-Kristen and Rudolf (2010) measure the effectiveness of monetary policy by comparing market rates and a riskless one-month repo rate, and empirically demonstrate that market interest rates (which are more volatile than the repo rate) bring about more stable target macroeconomic variables. Woodford (2012) states that monetary policy can affect financial stability if inflation targeting is set more flexibly, that is, to account for financial stability concerns. Gnan, Kokoszczynski, Lyziak, and McCauley (2011), Lenza, Pill, and Reichlin (2010) and Mishkin (2011) provide information about global macroprudential policy implementations and monetary policy experiences post-crisis.

When designing macroprudential policies and measuring their effects, the policy transmission mechanism between the financial and real sectors must be fully understood and adequately noted. Because the real sector does not directly follow central bank decisions, the immediate impact of these decisions should be borne first by banks. For this reason, proper liquidity management is key. Bernanke and Gertler (1995) separate the transmission mechanism of monetary policy to the banking sector into two channels: (1) balance sheet and (2) bank lending. In a survey carried out by the Basel Committee (Foglia \& Hancock, 2011), the transmission mechanism between the real and financial sectors is divided into three channels: (1) borrower balance sheet, (2) bank balance sheet and (3) liquidity. Therefore, for the transmission process (which is of concern to central banks), bank balance sheet and liquidity channels can be considered the same. Central banks' direct interventions through required reserve ratios or directive alterations to short-term interest rates by liquidity management operations would create incentives for banks to either keep their assets liquid or to fund the real sector to acquire capital gains. This situation means that the monetary authority would have the power to influence the amount of credit used by the real sector (Bernanke \& Blinder, 1988). In this context, Cetorelli and Goldberg (2012) empirically show that with a lending channel mechanism that accounts for crossborder bank affiliation, the effectiveness of liquidity shocks created by monetary policies is much larger in size and scope.

The CBRT was using short-term interest rates as the main macroeconomic policy tool until the effects of the global financial crisis reached the country through a surge of capital inflows. Although the interest rate policy was successful at decreasing Turkey's inflation rate to single digits for the first time in more than three decades, the rate was still significantly higher than developed and developing countries' averages at the onset of the global crisis. However, restraining the high current account deficit was a prerequisite to using a short-term interest rate tool, if indeed that tool was intended to further decrease the inflation rate, but as a side effect, it could also have been increasing portfolio investments.

Following the 2007/2008 crisis, the CBRT announced that it perceived the volume of domestic credits and the level of the exchange rate as transmission channels (Kara, 2012). Therefore, deviating average short-run interest rates from a policy rate to an 
unpredictable measure, in addition to managing the required reserves, has become the core of the CBRT's policy design so as to affect the liquidity of assets that can be lent. In this paper, we suggest that the volatile nature of short-term interest rates is an important component for tying together the CBRT's policy intentions, transmission mechanisms and target variables. ${ }^{2}$ If this is true, then introducing short-term interest rate volatility should cause banks to keep their balance sheets more liquid, which would eventually reduce the amount of domestic credit and thus the output growth rate. In this paper we try to understand whether short-term interest rate volatility affects economic performance. Here, the policy option for the CBRT is to introduce (or not) interest rate volatility, that is, to fix the short-term interest rate (or not) regardless of whether short-term interest rate is the policy option. If interest rate volatility affects economic performance, then to the extent that the CBRT affects this volatility, it will be able to affect economic performance. However, we want to show that higher interest rate volatility mimics some of the properties of tight monetary policy. Although a natural result of a contractionary policy could be expected to be domestic currency appreciation, if supported by the reserve options mechanism (ROM), ${ }^{3}$ higher volatility could create incentives for Turkish banks to keep their lira-denominated required reserves in foreign currency, which would eventually lead to a depreciation of the domestic currency. On the other hand, considering that the essential target of the policy maker is price stability, the effect of introducing a volatility policy on prices should logically be negative (because Turkey's inflation rate is considerably higher than developed and developing country averages) or close to zero; however, the real impact of a volatility policy can be identified by decomposing the net effect of exchange rate pass-through and level of depreciation. The empirical evidence gathered from Turkey suggests that higher interest rate volatility increases interest rates, depreciates the domestic currency and decreases credit growth and output. The effect of interest rate volatility on prices is not statistically significant.

In the next section, we present the methodology used in this study and introduce the definition of short-run interest rate volatility we use. Section 3 summarizes the empirical results. Section 4, a separate but supplementary section following the empirical results, discusses the price response to interest rate volatility, and Section 5 concludes.

\section{Methodology and data}

We can assume that the Turkish economy can be represented by the Vector Autoregressive (VAR) model depicted in the following multivariate equation:

$$
G(\mathrm{~L}) Y_{t}=C(\mathrm{~L}) X_{t}+\varepsilon_{t}
$$

where $Y_{t}$ is a $n \times 1$ vector of the endogenous variables, $X_{t}$ is a $k \times 1$ vector of the exogenous variables, $\mathrm{L}$ is the lag operator, $G(\mathrm{~L})$ is an $n \times n$ and $C(\mathrm{~L})$ is an $n \times k$ matrix of the polynomial of the lag operator and $\varepsilon_{t}$ is a $n \times 1$ vector of the structural disturbances with $\operatorname{Var}\left(\varepsilon_{t}\right)=\Lambda$, where $\Lambda$ is a diagonal matrix. Moreover, the above specification can be expressed by a structural VAR model as

$$
Y_{t}=A(\mathrm{~L}) Y_{t}+B(\mathrm{~L}) X_{t}+e_{t},
$$


where $e_{t}$ is a vector of the shocks. Here, $A(\mathrm{~L})$ and $B(\mathrm{~L})$ are polynomial matrices and $e$ is a vector of the reduced form error terms with $\operatorname{Var}\left(e_{t}\right)=\Sigma$. Let's define $G(\mathrm{~L})$ by the sum of the contemporaneous coefficient of the matrix of the structural equation $F$ and its coefficient $H(\mathrm{~L})$ :

$$
G(\mathrm{~L})=F+H(\mathrm{~L})
$$

Thus, we can write

$$
A(\mathrm{~L})=-F^{-1} H(\mathrm{~L}) \text { and } B(\mathrm{~L})=F^{-1} C(\mathrm{~L}) .
$$

Thus, $e=F^{-1} H(\mathrm{~L})$ and $B(\mathrm{~L})=F^{-1} C(\mathrm{~L})$, which implies $\sum=F^{-1} \Lambda F^{-1}$. Here, we follow Sims (1980) and the Cholesky decomposition to identify the $\varepsilon_{t}$ system. We assume $F$ will have zero elements in the upper triangular part, indicating that the latter shock affects the previous shock but the reverse hypothesis cannot be rejected. (One can refer to Enders (2010, pp. 297-329) and Lutkepohl (2006) for detailed explanations on VAR representations and transitions.) Thus, the order of the variables becomes important. Here we define

$Y_{t}=\left[\right.$ Volatility $_{t}$ Exchange Rate $_{t}$ Interest Rate $_{t}$ Industrial Production $_{t}$ Prices $_{t}$ Credit $\left._{t}\right]$,

and $X_{t}$ includes the constant term, 11 seasonal dummies and 4 crisis dummies. In ordering, we assume that there is no contemporaneous effect of macroeconomic variables on volatility, but that volatility affects macroeconomic variables contemporaneously. ${ }^{4}$ Moreover, if one considers that the interest rate is the CBRT's basic policy tool, then there is no contemporaneous effect of output and prices on the interest rate, but the interest rate affects those variables. The benchmark is a six-variable VAR model and the order of the variables is volatility, exchange rate, interest rate, industrial production, prices and credit. The lag order of the system is two, as suggested by the Bayesian information criteria. All variables in the system enter the VAR specifications in their logarithm, except volatility and the interest rate, which are in their levels. ${ }^{5}$

Although the variables for each specification of the model are presented in Appendix in detail, it is worth noting the basic variables here. We follow Merton (1980) and Andersen, Bollerslev, Diebold, and Labys (2003) and use the realized interest rate to calculate volatility. Thus, interest rate volatility is obtained by taking the standard deviation of the daily CBRT's interbank overnight interest rates from the previous month as a proxy. Using the previous month's daily data for the current month solves the identification problem that the current month's interest rate affects the current month's volatility measure. ${ }^{6}$ Output and prices are represented by the Industrial Production Index (industrial production) and Consumer Price Index (CPI) (prices), respectively. The interest rate variable (interest rate) is put into the model as overnight interbank interest rates until August 2010, and as overnight borrowing cost thereafter, due to the CBRT's policy shift on the given breakpoint date. To check for credit response, we use the banking sector's domestic credit volume, excluding bank credits to other banks (credits). We introduce the exchange rate variable in 
the model as the domestic currency value of the official exchange basket (0.5 USD + 0.5 Euro), ${ }^{7}$ which the CBRT has been following in its operations (exchange rate). All data are of monthly frequency and gathered from the CBRT Electronic Data Delivery System (EDDS) ${ }^{8}$ from January 1992 to December 2013, including both ends. ${ }^{9}$ We include dummy variables to incorporate crisis periods (namely, April 1994, November 2000 and February 2001) in the Turkish economy and include 11 monthly seasonal dummies to account for seasonality. Turkey experienced a self-inflicted financial crisis in April 1994. With high inflation, Turkey adopted an exchange-rate-based disinflation program in December 1999. This program faced a major speculative attack during November 2000 and failed in February 2001. We include two dummy variables for these events. The dummy variable for October 2011 is due to the change in the source of the overnight interest rate data. Prior to this date we gather data from the CBRT interbank market, and after this date from the Borsa Istanbul interbank market because that is when the CBRT began to benefit from the corridor system and implemented an average funding rate for signaling to the market.

\section{Empirical evidence}

We estimate a battery of VAR models, generated with slightly different specifications, to observe the effects of interest rate volatility on macroeconomic variables. In Figures 1-10, we present the resultant impulse responses of the variables of interest in the wake of a one-standard-deviation shock given to interest rate volatility, depending on the model specifications. We report the impulse responses for an 18-month horizon. ${ }^{10}$

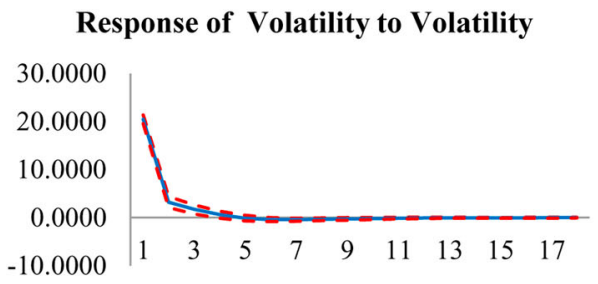

Response of Interest Rate to Volatility

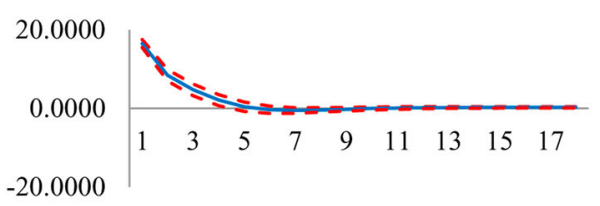

Response of Prices to Volatility

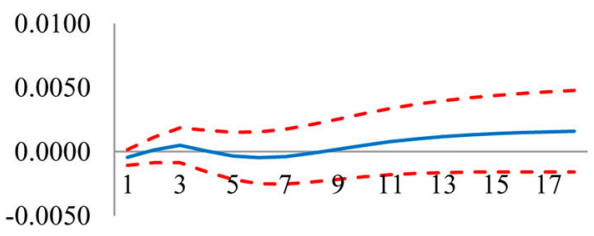

Figure 1. Response functions to volatility.

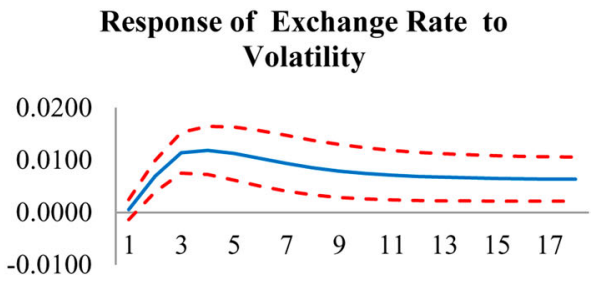
Response of Industrial Production
to Volatility

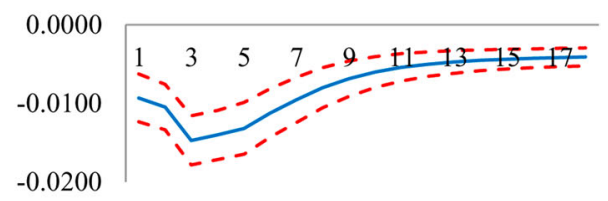

Response of Credits to Volatility

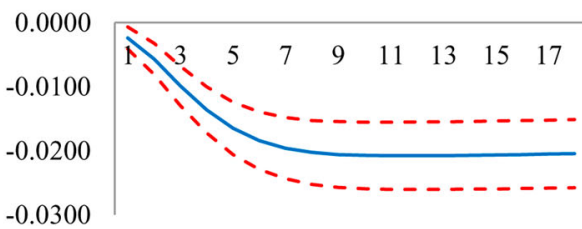


Response of Volatility to Volatility

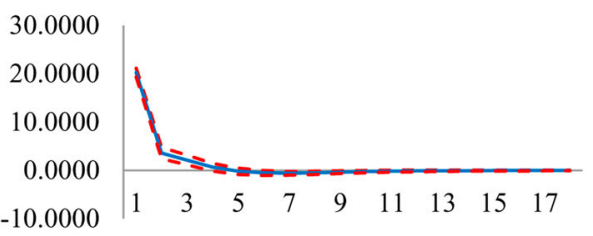

Response of Interest Rate to Volatility
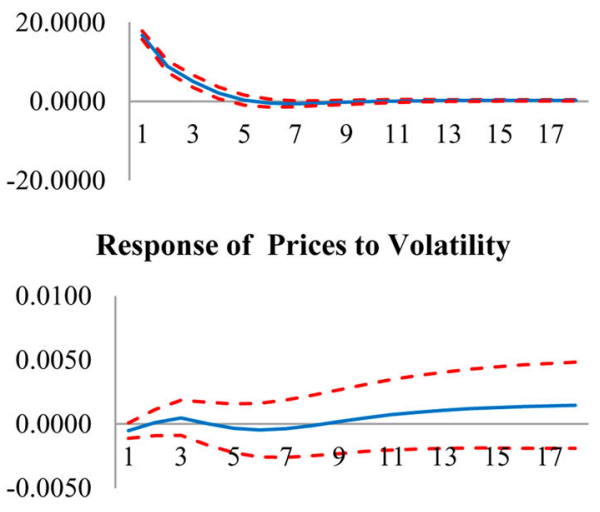

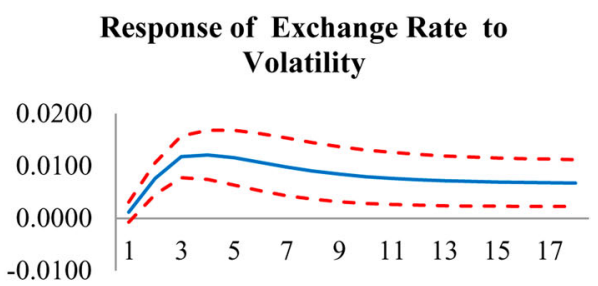

Response of Industrial Production to Volatility

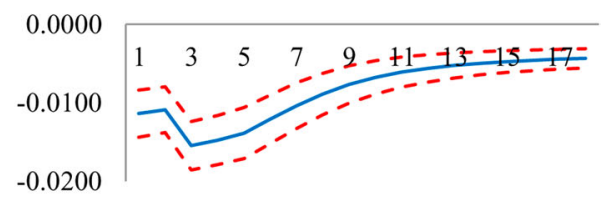

Response of Credits to Volatility

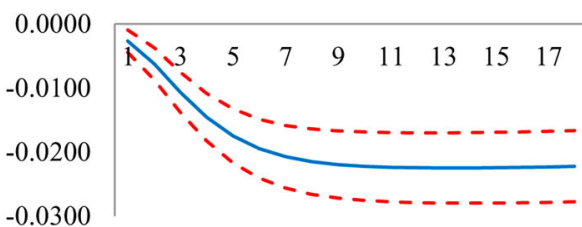

\section{Response of Current Account to Volatility}

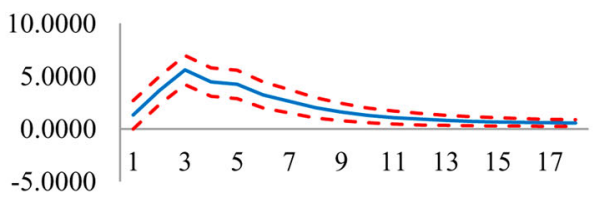

Figure 2. Response functions to volatility including current account surplus.

The middle lines are the medians and the other two lines stand for one-standard-deviation confidence bands.

Figure 1 suggests that a one-standard-deviation shock given to volatility increases the exchange rate (in other words, causes depreciation), and this effect is statistically significant for the 18 periods we consider. Similarly, a volatility shock increases interest rates, though the significance of this effect lasts only for four consecutive periods. Volatility has a reducing effect on the level of domestic credits and output (industrial production in our model), and a statistically significant decrease in these variables lasts for the full 18 periods. However, we do not find a statistically significant effect of volatility on prices.

All the evidence presented here is the set of reasonable reactions that one expects from a tight monetary policy, except for the exchange rate and prices. A statistically insignificant effect of higher volatility on prices is common, and we elaborate on this issue later in the paper. The effect of volatility on the exchange rate, however, is what the CBRT intended: widening the interest rate corridor increased interest rate volatility, discouraged speculative capital inflows and encouraged a longer deposit 


\section{Response of Volatility to Volatility}

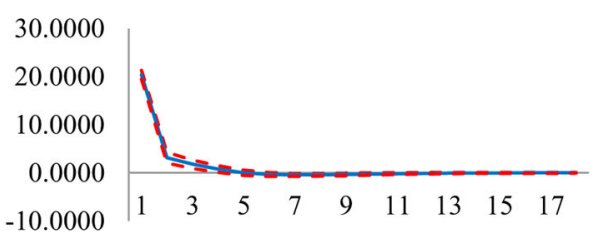

Response of Industrial Production to Volatility

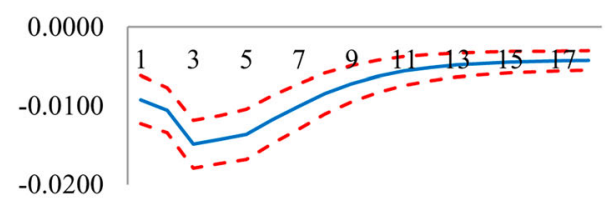

Response of Credits to Volatility

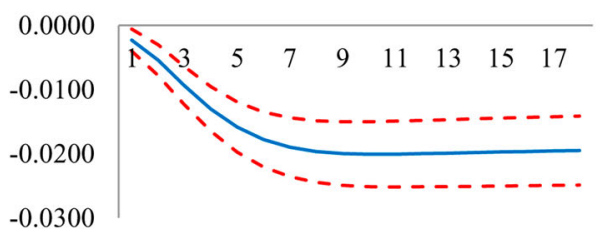

Response of Interest Rate to Volatility

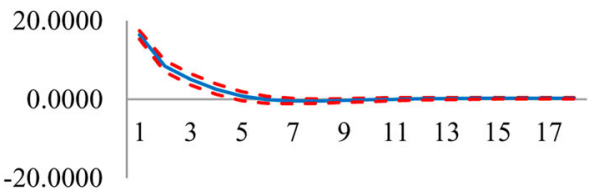

Response of Prices to Volatility

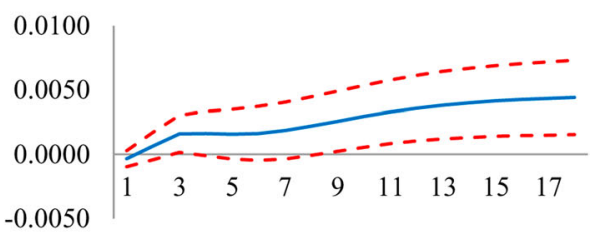

Response of REER to Volatility

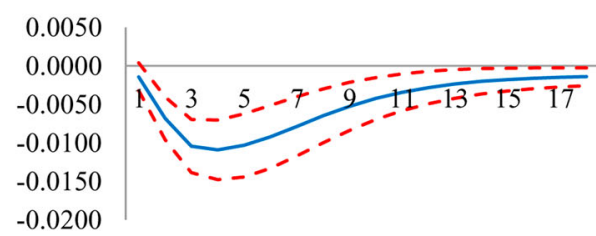

Figure 3. Response functions to volatility using the central bank's official REER.

Response of Volatility to Volatility

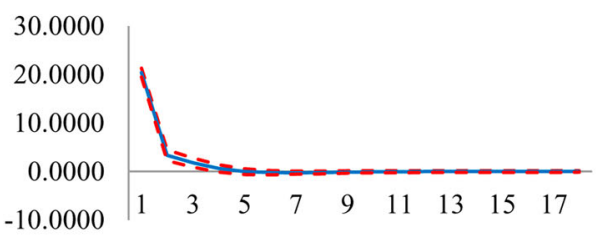

Response of Interest Rate to Volatility

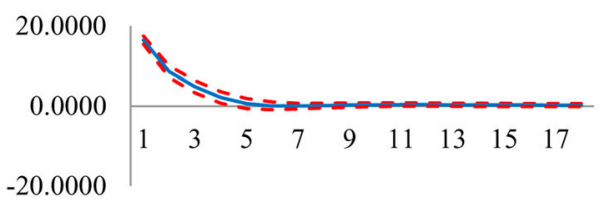

Response of Prices to Volatility

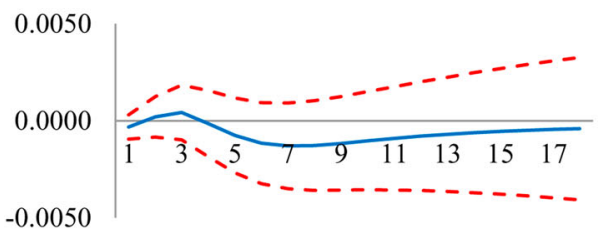

Response of Exchange Rate to Volatility

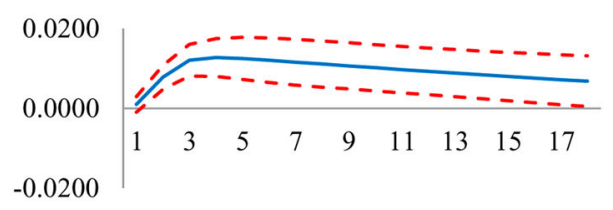

Response of Industrial Production to Volatility

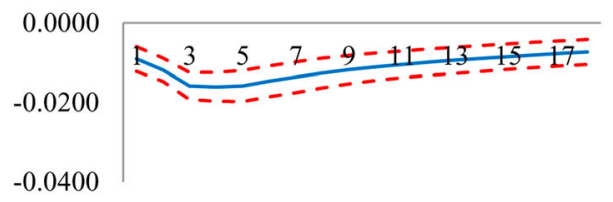

Response of Liquidity to Volatility

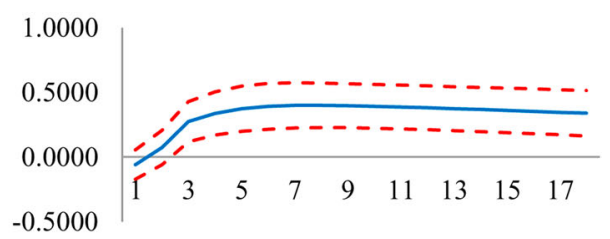

Figure 4. Response functions to volatility with Bank's liquidity. 


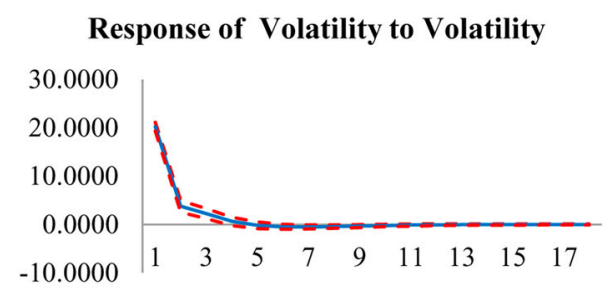

Response of Interest Rate to Volatility

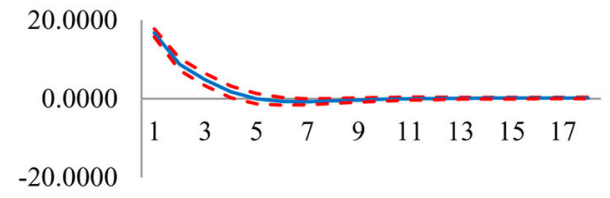

\section{Response of Prices to Volatility}

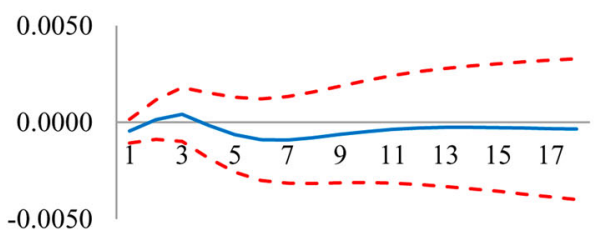

Response of Credits to Volatility

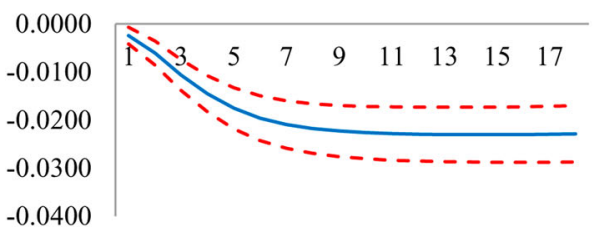

\section{Response of Exchange Rate to Volatility}

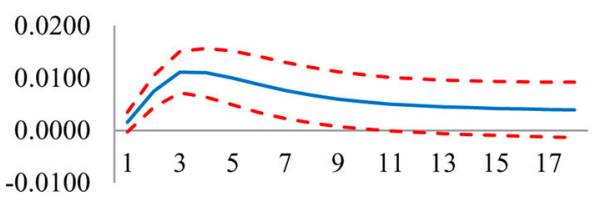

Response of Industrial Production to Volatility

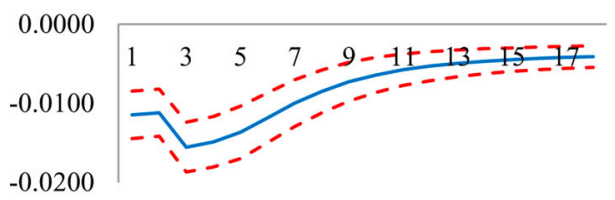

Response of Liquidity to Volatility

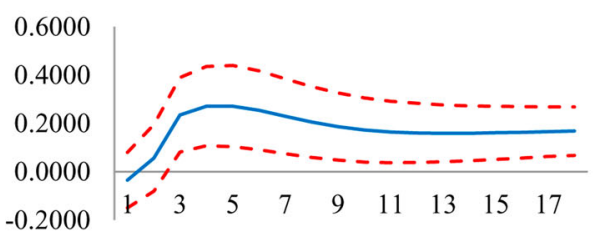

Response of Current Account to Volatility

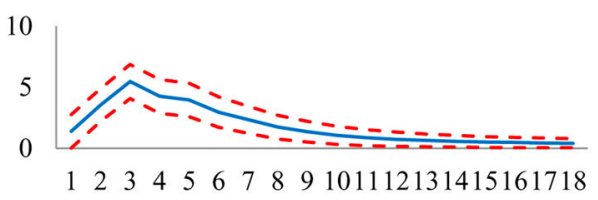

Figure 5. Response functions to volatility with liquidity and current account surplus.

maturity (Basci \& Kara, 2011, pp. 21-22; Bulletin, 2012a). Therefore, the CBRT considered the valuation of the Turkish Lira as an indicator, and used interest rate volatility as a tool to indirectly strengthen its control over the foreign exchange market (see also CBRT, 2013).

We modified the benchmark model by taking into account some additional indicators and supporting policy tools. In this regard, referring to the current account deficit's interrelation with financial stability, the CBRT publicly disclosed that it has adopted a set of policies to decrease the former. In addition, because there is a high correlation between capital inflows and GDP growth rates in Turkey (Akcelik, Basci, Ermisoglu, \& Oduncu, 2013, Figure 5, p. 8), the CBRT has begun to monitor credit market and short-term capital inflows. A balanced growth policy linked to a smooth and limited credit expansion has been added to the other aims of Turkey's monetary policy. In fact, the CBRT has been very diligent in sharing expectations regarding growth in overall credit volume. Some CBRT working papers, such as Kara, Kucuk, Tiryaki, and Yuksel (2013) and Kara and Tiryaki (2013), maintain 
Response of N.Volatility to N.Volatility

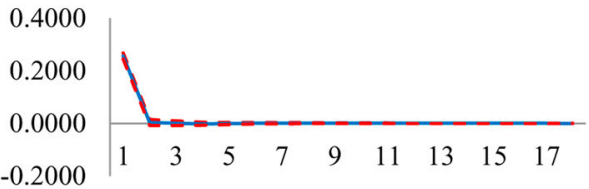

Response of Interest Rate to N.Volatility

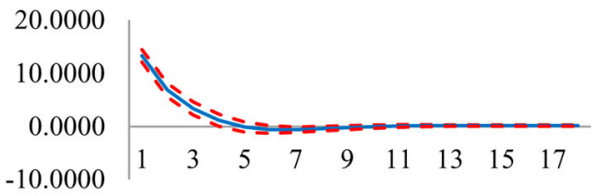

Response of Prices to N.Volatility

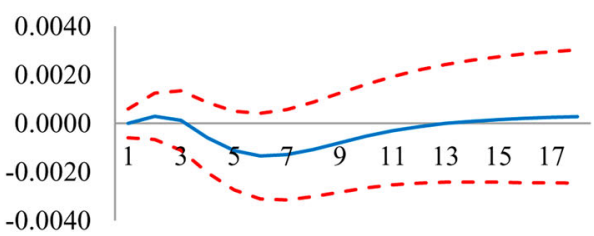

Response of Exchange Rate to N.Volatility

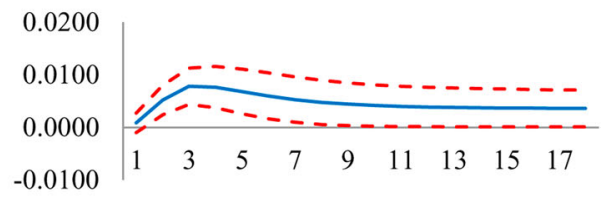

Response of Industrial Production to N.Volatility

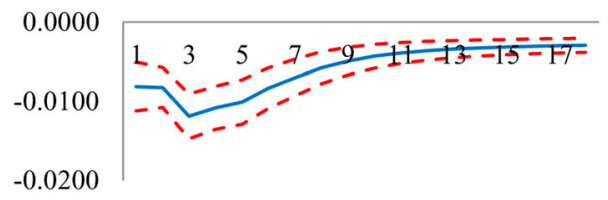

Response of Credits to N.Volatility

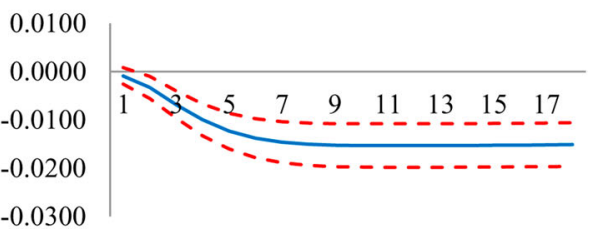

Figure 6. Response functions to the normalized volatility measure.

Response of Volatility to Volatility

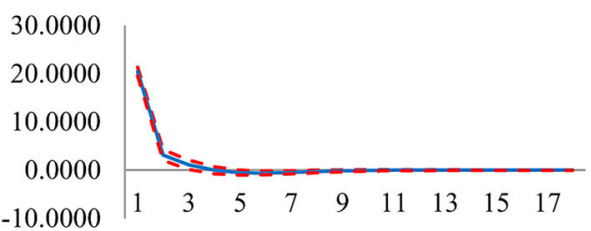

Response of Interest Rate to Volatility

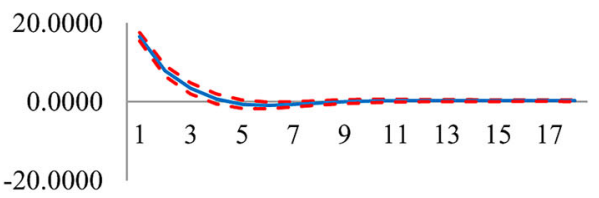

Response of WPI to Volatility

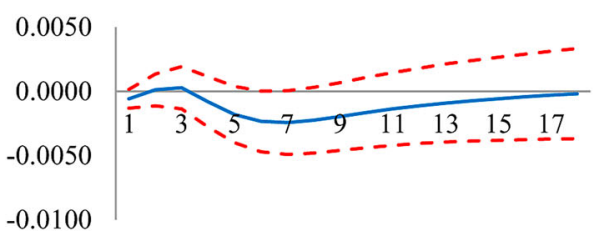

Response of Exchange Rate to Volatility

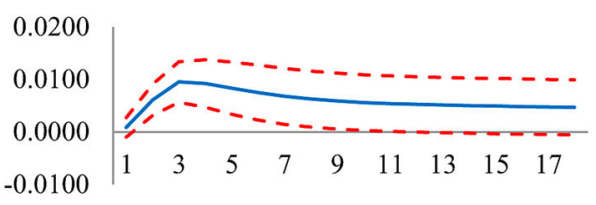

Response of Industrial Production to Volatility

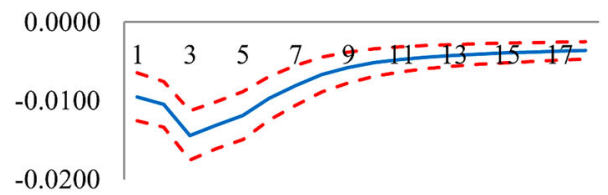

Response of Credits to Volatility

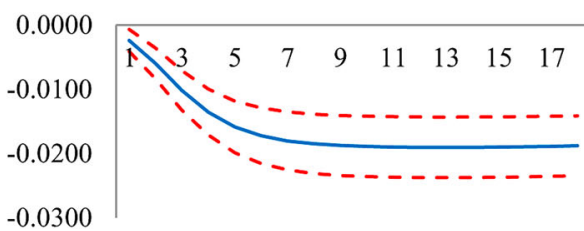

Figure 7. Response functions to volatility with WPI. 

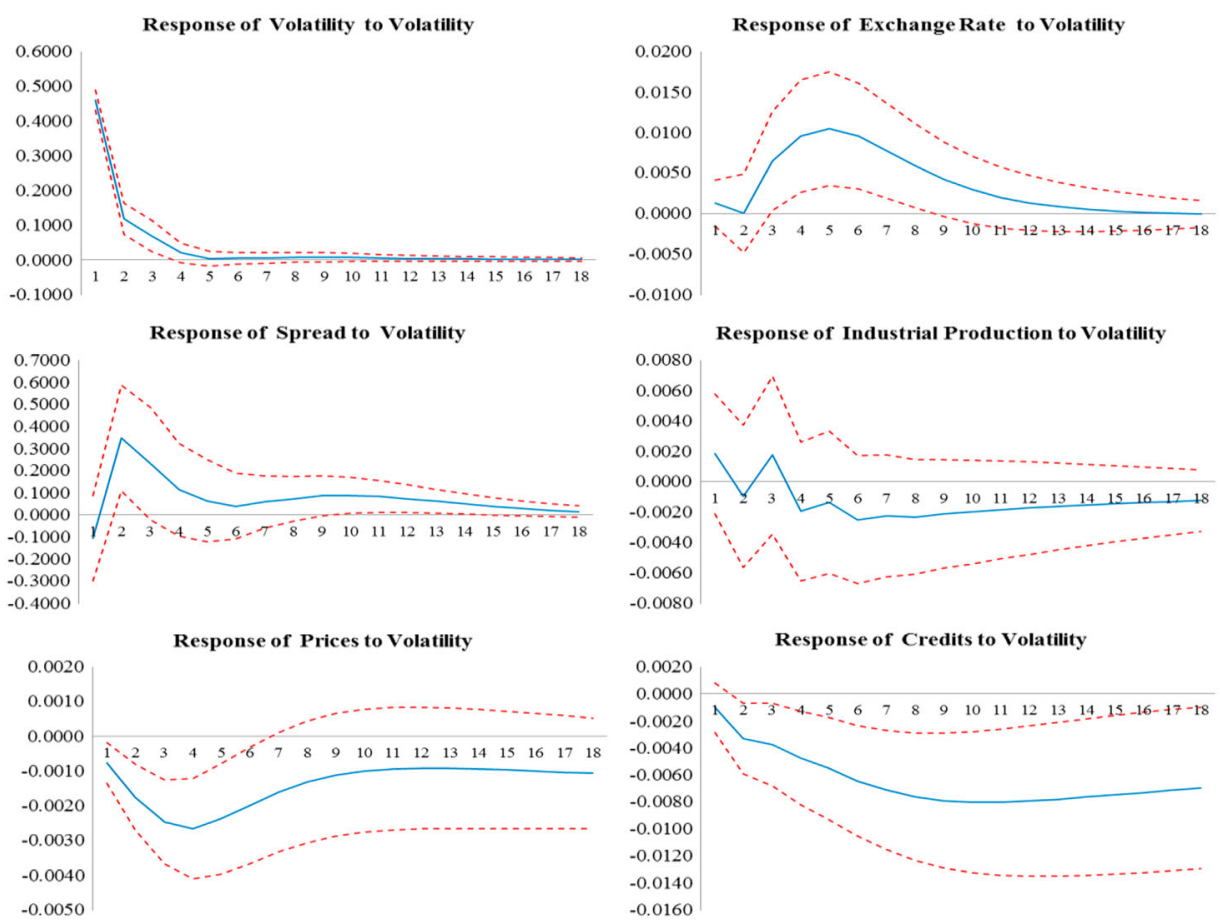

Figure 8. Post-2002-Era estimates with one-standard-deviation confidence bands.
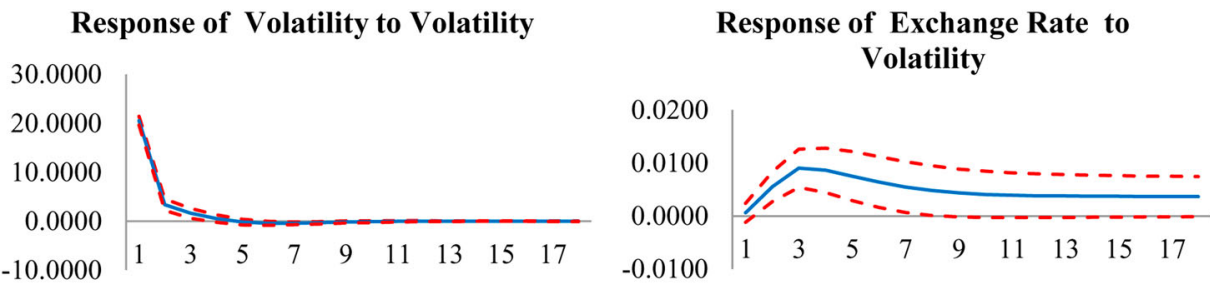

\section{Response of Interest Rate to Volatility}

\section{Response of Industrial Production to Volatility}
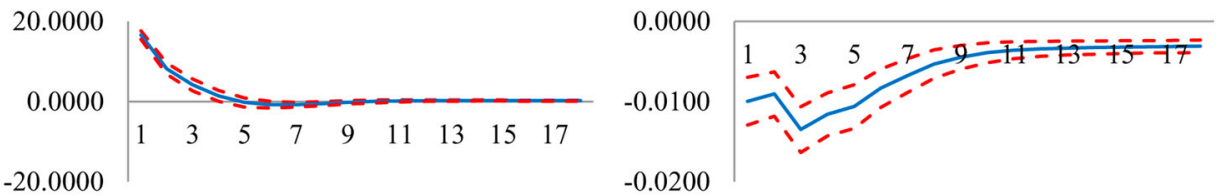

\section{Response of Prices to Volatility}

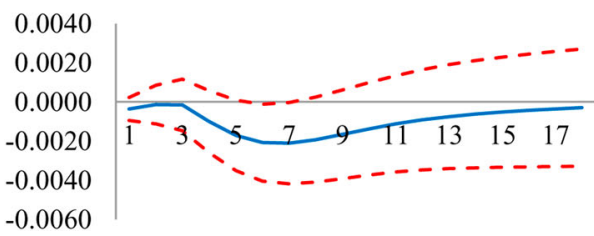

\section{Response of Credits to Volatility}

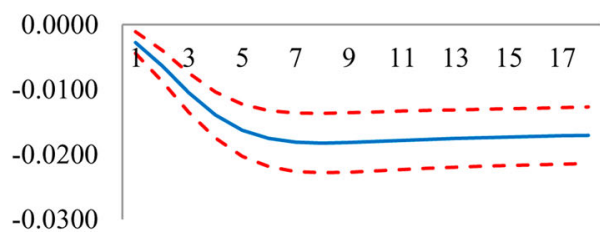

Figure 9. Response functions to volatility with VIX. 


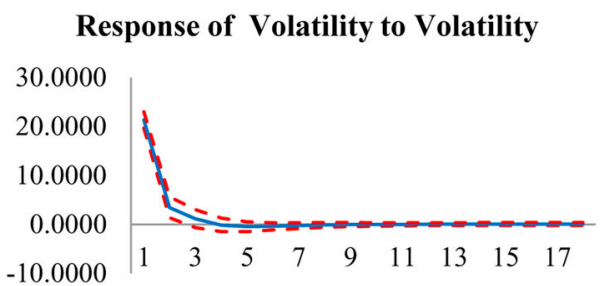

Response of Interest Rate to Volatility
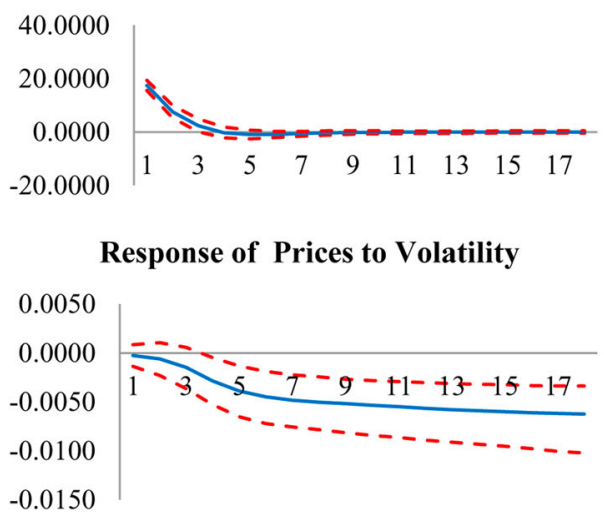
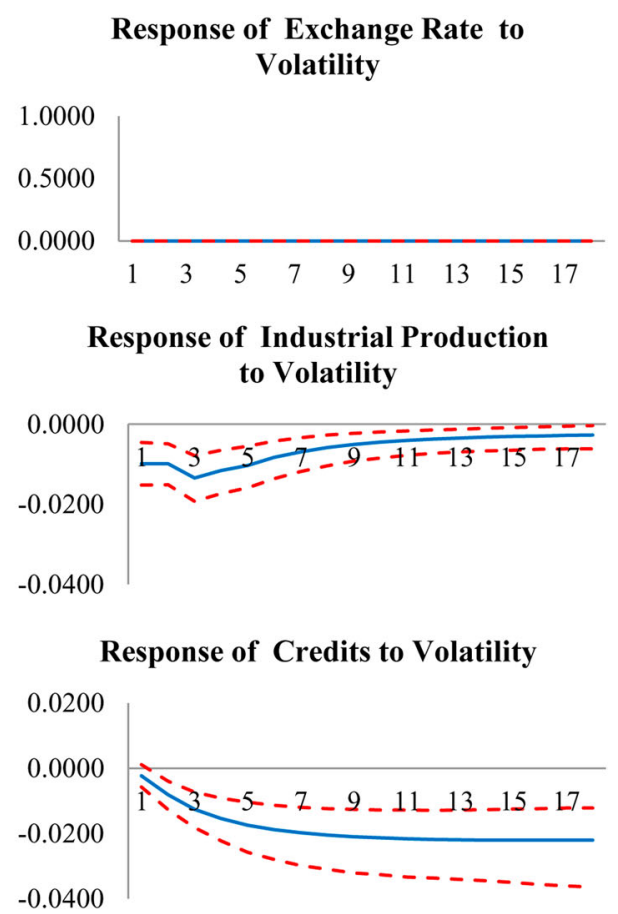

Figure 10. Responses to volatility when the exchange rate channel shuts down.

that a sustainable credit growth rate for Turkey should have been 15\% in 2013 and even lower in subsequent years. As an innovative and stabilizing policy tool, the ROM is being utilized to decrease capital volatility, strengthen reserves and stabilize movements in the credit market (Bulletin, 2012b).

These policy actions and concerns may all affect interest rate volatility; therefore, we include the ratio of the monthly current account deficit to the lag value of the interpolated monthly GDP and present the impulse responses in Figure $2^{11}$ (we take the lag value of GDP to avoid simultaneity). The estimates transferred from the benchmark specification are robust. Moreover, the evidence suggests that the new variable (current account) improves statistically significantly after the first period and that the effect lasts up to 11 periods.

The CBRT is also concerned about the real effective exchange rate (REER) level (CBRT, 2012, pp. 16-18), and so we include this variable in the analysis in place of the exchange rate basket in the kernel. Because the REER calculation accounts for the domestic price level, we place this variable last in the VAR order. We use the official REER data that the CBRT calculates and publicly announces on its website (http:// tcmb.gov.tr/yeni/eng/). Figure 3 presents the corresponding impulse responses. By definition, and in contrast to the exchange rate basket, a decrease in REER should be interpreted as depreciation rather than appreciation. Again, the evidence for the interest rate, industrial production and credits are robust. Moreover, with the new exchange rate variable, a one-standard-deviation shock to volatility depreciates the local currency yet again. This effect is statistically significant for the 18 periods that we consider. 
To restrain domestic credit growth, the CBRT occasionally increases the required reserve ratio (in addition to adjusting the reserve option coefficients) to create additional borrowing costs for banks. Thus, we also incorporate a measure in our model with the intention of assessing banks' liquidity positions. The new measure (Liquidity) is generated by taking into account the Basel definitions used to set the criteria related to liquidity (i.e. liquidity requirements), legal ratios set by the Banking Regulation and Supervision Agency or by using our own interpretation. Accordingly, (Liquidity) is derived as follows: [Vault Cash + Foreign Banknotes + Cash in Transit + Checks Received + Securities Due + Precious Metals (FX) + Claims On Central Bank + Claims on Banks + Claims on Money Market Transactions + Securities at Fair Value Through Profit or Loss and Securities Available for Sale]/Total Assets. We replace the new liquidity measure with the domestic credit volume, and present the impulse responses in Figure 4. The responses of the five variables are still robust. The impact on banks' liquidity is initially negative, but it increases in subsequent periods. These effects are statistically significant after the second period.

Figure 5 presents the results of the VAR estimation where liquidity, credits and current account surplus variables are added to the benchmark specification simultaneously. The results from the previous analyzes are robust.

To further elaborate on the effect of interest rate volatility on prices, we note the odd course of Turkey's price inflation in this study's data coverage. For decades, Turkey experienced high levels of consumer price inflation. Between 1992 and 2004, for example, average inflation was $64.30 \%$ annually. Bringing inflation under control became a goal for the CBRT, and between 2005 and 2012, this average diminished to $8.39 \%$ annually (except for in 2010). Thus, the source of interest rate volatility might be Turkey's high interest rates, which have been used as a monetary policy tool as part of the campaign against high inflation. To account for this possibility, we deflate the volatility with the lagged value of the interest rate. (The results are almost identical when we also deflate the volatility with the current interest rate.) Figure 6 presents the corresponding impulse responses, and the results are robust.

As an alternative measure of price inflation, the CBRT also occasionally followed and targeted the Wholesale Price Index (WPI) ${ }^{12}$ instead of the CPI. Figure 7 presents the corresponding impulse response functions produced by replacing the CPI with the WPI; the estimates are still robust and the effect of volatility on prices is still not robust.

Turkey underwent substantial structural reforms after the 2001 financial crisis, which is why Figure 8 presents the impulse response functions beginning in 2002:1. Here, following Berument, Ceylan, and Dogan (2014), to capture the monetary policy stance, we use the spread between the overnight interest rates and the treasury auction interest rates, which can be a measure of monetary policy because it exhibits a signaling feature by comprising information on the CBRT's funding cost relative to market expectations. The estimates from the benchmark specification are robust. ${ }^{13}$

The source of volatility that we use may not be policy driven but exogenous. To control for the international risk appetite we include volatility index (VIX) as an exogenous variable in various forms, such as its level, current and first lags, log, etc. All the impulse responses are robust to our benchmark specification; however, we only report the impulse responses when VIX enters the system as an exogenous variable as its current and first lags (Figure 9). ${ }^{14}$ 


\section{Discussion on the effect of interest rate volatility on prices}

The impulse responses provided above show that although we cannot find a statistically significant effect of interest rate volatility on prices, we observe that interest rate volatility decreases output, credit volume and the current account surplus. The statistically insignificant effect on prices is worth discussing, and we present a set of reasons for this outcome below:

(1) There is an effect of interest rate volatility on prices but we cannot find it (Type-II error).

(2) There is no effect of interest rate volatility on prices and thus we cannot find one. This hypothesis is parallel to the CBRT's 'multiple tools for multiple objectives' policy (Kara, 2012), even if the CBRT did not explicitly state the reasons why prices do not move.

(3) The transmission channels of interest rate volatility to macroeconomic variables might have a canceling effect as the domestic currency depreciates, which would increase prices via the exchange rate pass-through. However, depreciation itself may decrease output demand and total credit, thus depreciation may have a canceling effect on prices. To assess this, following the method suggested by Bernanke, Gertler, and Watson (1997), we shut down the effect of interest rate volatility on the exchange rate. That is, we seek the answer to the following question: 'How would interest rate volatility affect economic performance (the rest of the macro variables) if the exchange rate was not responding to volatility?' According to the presented estimates in Figure 10, volatility increases interest rates for four periods, and this effect is statistically significant for the first three periods. Volatility decreases output for 18 periods, and this effect is statistically significant. It also decreases prices, and this effect is statistically significant after the fourth period. Finally, volatility decreases credit volume statistically significantly and permanently. From these results, we can claim that once the exchange rate is accounted for, interest rate volatility mimics what is expected from a tight monetary policy and can be adopted as one policy tool within an environment of multiple tools and objectives.

\section{Conclusions}

This paper aims to propose a new policy tool for central banks to conduct their monetary policies: interest rate volatility. The validity of this tool is demonstrated after examining the CBRT's policy scheme and after its public disclosures aiming at market orientation. According to our observations, it seems that intentionally introducing interest rate volatility through a mix of officially announced tools (in this case, credit policy, interest rate policy and liquidity policy) can be an effective monetary policy. Here, we do not argue that the CBRT control interest rate volatility. The option that the interest rate is not kept constant but allowed to change daily is the policy decision. Then higher interest rate volatility affects economic performance. To the degree that CBRT affects this volatility (along with market participants) might be used as a policy tool; this is an option that we did not intend to capture in this paper. 
We use the daily standard deviation of interbank interest rates from the previous month as a proxy for interest rate volatility to attempt to prove this observation. We examine the effects of a one-standard-deviation shock to volatility over a set of macro variables within a VAR framework. The empirical results indicate that interest rate volatility is potent for the basic macro variables that monetary policy generally controls.

Accordingly, interbank interest rate volatility depreciates domestic currency, increases interest rates and reduces the level of domestic credits and output. These statistically significant results are robust for various modified models by means of additional assumptions. For instance, impulse responses obtained by considering the monetary authority's current account surplus, REER and liquidity targets give expected results without deteriorating the estimated results of the benchmark.

One disputable result emerges: a statistically insignificant effect on prices. Although there are some reasonable explanations for this complication, we hypothesize a sterilized effect of volatility on prices (ceteris paribus), and to try to prove this, we hypothetically shut down the exchange rate channel. With this additional assumption, interest rate volatility has a statistically significant downward effect on prices in addition to the above-mentioned effects on the other basic macroeconomic variables.

\section{Acknowledgements}

The authors would like to thank Rana Nelson and two anonymous referees for their valuable comments on the paper.

\section{Disclosure statement}

No potential conflict of interest was reported by the authors.

\section{Notes}

1. See IMF (2012) for such macroprudential polices.

2. Central banks may also choose to decrease rather than increase interest rate volatility to mitigate obscured monetary policy signals, to promote a rapid and predictable monetary transmission mechanism and to help market participants better manage their economic and financial risks (see e.g. Gray and Talbot, 2006; Van't dack, 1999). Here, we intend to document the effect of introducing interest rate volatility into the central bank policy arsenal. Interest rate volatility is a tool like any other policy tool that central banks have, with some promotional and some adverse effects on economic variables. We thank the anonymous referee for pointing the incentive that central banks may have to decrease interest rate volatility.

3. The ROM is given to banks to keep foreign currency and/or gold up to the officially announced level of domestic-currency-denominated reserve requirements. Banks are allowed (though not obliged) to keep 60\% of their required Turkish Lira (TL) reserves as foreign exchange (in Euros and US Dollars (USD)) and an additional 30\% as gold. As of May 2013, the first $35 \%$ of the allowed foreign exchange partition of the required domestic currency reserves is accepted by being multiplied by 1.4. The coefficients for each subsequent $5 \%$ increase are $1.7,2.1,2.4,2.6$ and 2.7 , respectively. While the first $15 \%$ of the gold allowance is accepted as $1-1.4$, the following three subsequent $5 \%$ increases are accepted with coefficients of $1.5,2$ and 2.5 , respectively.

4. Developments in the current month also affect interest rate volatility. We address this issue by how we calculate interest rate volatility, taking the standard deviation of daily interest 
rates from the previous period for the current period. Note that this variable enters the specification as the first variable. Alternatively, we could take the standard deviation of daily interest rates within the same period and insert this variable into the VAR specification as the last variable in the Cholesky ordering. Thus, these two specifications employ the same identification assumptions. To obtain the identical impulse responses as in the former specification, it is necessary in the latter specification that all variables have two lags but that the volatility variable has three lags in the VAR specification. When we compare the impulse responses of the two specifications that have two lags, we see that our specification produces impulse responses with slightly lower confidence intervals.

5. If all series are $\mathrm{I}(0)$ or some series are $\mathrm{I}(0)$ and some are $\mathrm{I}(1)$ but the system is cointegrated, then VAR in its level is appropriate (see Lutkepohl \& Reimers, 1992; Sims, Stock, \& Watson, 1990). Even if we get mixed results for the unit root test across variables, we fail to reject the no-cointegrating vector. Thus we perform the analyses in levels. The results of these tests are not reported here to save space but are available from the authors upon request.

6. There are other statistical methods to calculate volatility, such as ARCH/GARCH-type models, Kalman filters, etc. Each of these captures a different component of uncertainty (see e.g. Berument \& Yucel, 2005; Bomberger, 1996). However, using daily data allows us to capture the observed volatility rather than the perception of it (ARCH/GARCH-type models) or specification instability (Kalman filters).

7. The Euro was introduced in 1999; therefore for the period prior to 1999, we use the official convention between the Euro and the Deutsche Mark (DM) and use the basket as 0.5 USD $+0.974027 \mathrm{DM}$ to calculate the exchange rate.

8. http://evds.tcmb.gov.tr/cbt.html.

9. The CBRT has been explicitly implementing interest rate volatility as a monetary policy tool only since 2007/2008. However, depending on capital in- and out-flows, de facto interest rate volatility has existed in Turkish money markets since the early 1990s. Thus, we can still observe and assess the effects of volatility on economic performance in Turkey even though it was not a CBRT policy choice before 2008. For this reason, we extended our data range back to the early 1990 s.

10. Extending the time horizon up to 24,36 and 48 periods does not change the basic conclusion of the paper. Thus we end the impulse responses at the eighteenth period.

11. Due to data availability for GDP the sample ends in September 2013.

12. The Turkish Statistical Institute (TurkStat) discounted calculating the WPI after 2005; therefore, for the post-2005 period we replace and update the series with the Producer Price Index (PPI).

13. Due to a low degree of freedom, the lag order is set to one.

14. There might be other specifications. One of them is that the relationship could be non-linear. As an exercise we tried a Threshold VAR (TVAR) specification of our benchmark model (not reported here to save space) and it seems that the basic results of the paper are robust.

\section{Supplemental data}

Supplemental data for this article can be accessed here. http://dx.doi.org/10.1080/ 17938120.2016.1150009

\section{References}

Akcelik, Y., Basci, E., Ermisoglu, E., \& Oduncu, A. (2013). The Turkish approach to capital flow volatility (CBRT Working Paper No. 13/06). Ankara: Central Bank of the Republic of Turkey.

Andersen, T. G., Bollerslev, T., Diebold, F. X., \& Labys, P. (2003). Modeling and forecasting realized volatility. Econometrica, 71, 579-625.

Basci, E., \& Kara, A. H. (2011). Financial stability and monetary policy. İktisat, Işletme ve Finans (in Turkish), 26(302), 9-25.

Bernanke, B. S., \& Blinder, A. S. (1988). Credit, money, and aggregate demand. American Economic Review, American Economic Association, 78(2), 435-439. 
Bernanke, B. S., \& Gertler, M. (1995). Inside the black box: The credit channel of monetary policy transmission. Journal of Economic Perspectives, American Economic Association, 9 (4), 27-48.

Bernanke, B. S., Gertler, M., \& Watson, M. (1997). Systematic monetary policy and the effects of oil price shocks. Brookings Papers on Economic Activity, Economic Studies Program, the Brookings Institution, 28(1), 91-157.

Berument, H., Ceylan, B. N., \& Dogan, B. (2014). An interest-rate-spread-based measure of Turkish monetary policy. Applied Economics, 46(15), 1804-1813.

Berument, H., \& Yucel, E. M. (2005). Return and maturity relationships for treasury auctions: Evidence from Turkey. Fiscal Studies, Institute for Fiscal Studies, 26(3), 385-419.

Bomberger, W. A. (1996). Disagreement as a measure of uncertainty. Journal of Money, Credit and Banking, 28(3), 381-392.

Bulletin. (2012a, September). A new policy tool for central banks: Policy predictability. No. 24.

Bulletin. (2012b, December). Reserve option mechanism, Central Bank of the Republic of Turkey. No. 25.

Carvalho, C., Eusepi, S., \& Grisse, C. (2012). Policy initiatives in the global recession: What did forecasters expect? Current Issues in Economics and Finance, 18(2), 1-11.

CBRT. (2012, December). Monetary policy and exchange rate policy for 2013. Ankara: Central Bank of the Republic of Turkey.

CBRT. (2013, November). Financial stability report (Vol. 17). Ankara: Central Bank of the Republic of Turkey.

Cetorelli, N., \& Goldberg, L. S. (2012). Banking globalization and monetary transmission. The Journal of Finance, 67(5), 1811-1843.

Enders, W. (2010). Applied econometric time series (3rd ed.). Hoboken, NJ: Wiley.

Foglia, A., \& Hancock, D. (2011, February). The transmission channels between the financial and real sectors: A critical survey of the literature (Basel Committee on Banking Supervision Working Papers, No. 18) Basel: Bank of International Settlements.

Gerlach-Kristen, P., \& Rudolf, B. (2010). Macroeconomic and interest rate volatility under alternative monetary operating procedures (BIS Working Papers, No. 319). Basel: Bank of International Settlements.

Gnan, E., Kokoszczynski, R., Lyziak, T., \& McCauley, R. (Eds.). (2011). Monetary policy after the crisis. SUERF Studies. Vienna: Larcier.

Gray, S., \& Talbot, N. (2006). Monetary operations. Bank of England, handbooks in central banking, No. 10. London: Bank of England.

IMF. (2012, December). The interaction of monetary and macroprudential policies (IMF background paper). Washington, DC: International Monetary Fund.

Kara, A. H. (2012). Monetary policy in Turkey after the global crisis [Kuresel Kriz Sonrasi Para Politikasi] (Working papers 1217). Ankara: Research and Monetary Policy Department, Central Bank of the Republic of Turkey.

Kara, A. H., Kucuk, H., Tiryaki, S. T., \& Yuksel, C. (2013, January). In search of a reasonable credit growth rate for Turkey. CBRT Research Notes in Economics, No. 2013-03. Ankara: Central Bank of the Republic of Turkey.

Kara, A. H., \& Tiryaki, S. T. (2013). Credit impulse and economic growth cycles (in Turkish). CBRT Research Notes in Economics 1310, Ankara: Research and Monetary Policy Department, Central Bank of the Republic of Turkey.

Lenza, M., Pill, H., \& Reichlin, L. (2010). Monetary policy in exceptional times. Economic Policy, 25, 295-339.

Lutkepohl, H. (2006). New introduction to multiple time series analysis. New York, NY: Springer Publications.

Lutkepohl, H., \& Reimers, H. E. (1992). Impulse response analysis of cointegrated systems. Journal of Economic Dynamics and Control, 16(1), 53-78.

Merton, R. (1980). On estimating the expected return on the market: An exploratory investigation. Journal of Financial Economics, 8, 323-361.

Mishkin, F. S. (2011). Monetary policy strategy: Lessons from the crisis (NBER Working Papers 16755). Cambridge: National Bureau of Economic Research

Sims, C. (1980). Macroeconomics and reality. Econometrica, 48, 1-48. 
Sims, C. A., Stock, J. H., \& Watson, M. W. (1990). Inference in linear time-series models with unit roots. Econometrica, 58(1), 113-144.

Van’t dack, J. (1999). Implementing monetary policy in emerging market economies: An overview of issues (BIS Policy Papers No. 5). Basel: Bank of International Settlements.

Woodford, M. (2012). Inflation targeting and financial stability (NBER Working Papers 17967). Cambridge: National Bureau of Economic Research.

Appendix

\begin{tabular}{|c|c|c|}
\hline Variables & Explanation & Source \\
\hline Volatility & $\begin{array}{l}\text { We calculated volatility by taking the standard deviation of } \\
\text { the daily interest rate for each month. }\end{array}$ & $\begin{array}{l}\text { Own } \\
\text { calculation }\end{array}$ \\
\hline Interest rate & $\begin{array}{l}\text { Overnight interbank interest rate. Source Code: TP.PY.P06. } \\
\text { ON: Simple Interest Rate Weighted Average. For the post- } \\
\text { August- } 2010 \text { period we used borrowing cost. }\end{array}$ & CBRT, EDDS \\
\hline $\begin{array}{l}\text { Industrial } \\
\text { production }\end{array}$ & $\begin{array}{l}\text { Industrial Production Index }(1992=100) \text {. We updated the } \\
\text { data from the }(1997=100) \text { and }(2005=100) \text {-based series. }\end{array}$ & CBRT, EDDS \\
\hline Prices & $\begin{array}{l}\text { Consumer Price Index. Source Code: TP.FG.A01: General } \\
\text { Index, Consumer }(1987=100) \text {. We updated this price data by } \\
\text { the new basket for the post-2005 period. Source Code: TP. } \\
\text { FG.J0:0.General Price Index (Consumer Price, } 2003=100 \text { ). }\end{array}$ & CBRT, EDDS \\
\hline$W P I$ & $\begin{array}{l}\text { Wholesale price index. Source Code: TP.FG.E01.TOP: } \\
\text { Wholesale Price Index (General, } 1987=100) \text {. We updated } \\
\text { this price data by the new producer index for the post-2005 } \\
\text { period. TP.FG.TF01:1.GENEL: Producer Price Index } \\
(2003=100) \text {. }\end{array}$ & CBRT, EDDS \\
\hline Credits & $\begin{array}{l}\text { Source Code: TP.KM.C26:5 Banking Sector Domestic Credit } \\
\text { Volume }\end{array}$ & CBRT, EDDS \\
\hline Current account & Capital inflow/Capital outflow & CBRT, EDDS \\
\hline Capital inflow & Goods export + Service credits + Income credits & CBRT, EDDS \\
\hline Capital outflow & Goods import + Service debits + Income debits & CBRT, EDDS \\
\hline Exchange rate & 0.5 USD + 0.5 Euro & CBRT, EDDS \\
\hline$R E E R$ & Real CPI-based Exchange Rate & CBRT, EDDS \\
\hline New volatility & ${\text { Volatility/Interest } \text { Rate }_{t-1}}$ & CBRT, EDDS \\
\hline Spread & Interest Rate - Treasury Auction Interest Rate & $\begin{array}{l}\text { Own } \\
\text { calculation }\end{array}$ \\
\hline Liquidity & $100 \times$ Liqassets $/ \mathrm{K} 40$ & $\begin{array}{l}\text { Own } \\
\text { calculation }\end{array}$ \\
\hline Liqassets & $\mathrm{K} 1+\mathrm{K} 2+\mathrm{K} 3+\mathrm{K} 4+\mathrm{K} 5+\mathrm{K} 6+\mathrm{K} 7+\mathrm{K} 10+\mathrm{K} 13+\mathrm{K} 15$ & $\begin{array}{l}\text { Own } \\
\text { calculation }\end{array}$ \\
\hline Kl & TP.PB.K01: 1.Vault Cash & CBRT, EDDS \\
\hline$K 2$ & TP.PB.K02: 2.Foreign Banknotes & CBRT, EDDS \\
\hline K3 & TP.PB.K03: 3.Cash in Transit & CBRT, EDDS \\
\hline K4 & TP.PB.K04: 4.Checks Received & CBRT, EDDS \\
\hline K5 & TP.PB.K05: 5.Securities Due & CBRT, EDDS \\
\hline K6 & TP.PB.K06: 6.K Precious Stones (FX) & CBRT, EDDS \\
\hline K7 & TP.PB.K07: 7.Claims on Central Bank & CBRT, EDDS \\
\hline K10 & TP.PB.K10: 8.Claims on Banks & CBRT, EDDS \\
\hline
\end{tabular}


B. Dogan et al.

Appendix Continued.

\begin{tabular}{llc}
\hline Variables & \multicolumn{1}{c}{ Explanation } & \multicolumn{1}{c}{ Source } \\
\hline K13 & TP.PB.K13: 9. Claims on Money Market Transactions & CBRT, EDDS \\
K15 & TP.PB.K15: 11. Securities at Fair Value Through Profit or & CBRT, EDDS \\
& Loss and Securities Available for Sale & \\
K40 & TP.PB.K40: 34.Total Assets & CBRT, EDDS \\
\hline
\end{tabular}

